$5-1-2015$

\title{
Own-age bias in face-name associations: Evidence from memory and visual attention in younger and older adults
}

\author{
K.E. Dillon \\ Carla M. Strickland-Hughes \\ University of the Pacific, cstricklandhughes@pacific.edu \\ Robin Lea West \\ University of Florida, Gainesville \\ Natalie C. Ebner \\ University of Florida, Gainesville, natalie.ebner@ufl.edu
}

Follow this and additional works at: https://scholarlycommons.pacific.edu/cop-facpres

Part of the Psychology Commons

\section{Recommended Citation}

Dillon, K. E., Strickland-Hughes, C. M., West, R. L., \& Ebner, N. C. (2015). Own-age bias in face-name associations: Evidence from memory and visual attention in younger and older adults. Paper presented at Association for Psychological Science Annual Convention in New York, NY.

https://scholarlycommons.pacific.edu/cop-facpres/928 
Own-Age Bias in Face-Name Associations: Evidence from Visual Attention and Memory in Younger and Older Adults Kaitlyn Dillon', Carla M. Strickland-Hughes', Robin L. West't, \& Natalie C. Ebner' ${ }^{1}$ Department of Psychology, University of Florida

\section{Introduction}

memory

- Ability to successfully remember face-name pairs is an important social skill Naveh-Benjamin et al,, 2004

- Declines with age, possibly due to age-related deficits in associative memory Naveh-Benjamin et al, 2009 Own-age bias (OAB)

- Better face recognition for own- than other-age faces in younger \& older adults Rhodes \& Anastasi, 2012 - Increased attention to and more favorable evaluation of one's own-age group compared to other age groups Ebner, 2008; Ebner \& Johnson, 2009; Hackel et al., 2013

Longer and more frequent looking at encoding of own-age compared to other-age faces He et al, 201 OAB not yet examined for name memory and visual attention during encoding and testing

\section{Research Aims}

AIM 1. To determine the extent to which younger $(\mathrm{YA})$ and older $(\mathrm{OA})$ adults show an $O A B$ in a face-name associative memory paradigm for (1A) name memory overall and (1B) separately for name recognition and name recall.

AIM 2. To determine the extent to which $Y A$ and $O A$ show an $O A B$ in visual attention during (2A) encoding of face-name pairs, (2B) name recognition testing, and (2C) name recall testing.

\section{Methods}

Participants

- Healthy, well-educated, community-dwelling, Caucasian, English-speaking

- 90 YA ( $M=19.2, S D=1.31,71 \%$ female) and $84 \mathrm{OA}(M=73.4, S D=3.48,70 \%$ female $)$

FNA task

- High-frequency first names paired with neutrally-expressive faces Ebner et al,, 2010, SSA, 2012

- Presented in four same gender, different age (younger, older) blocks of twelve pairs

- Name recognition and name recall tested for half of the pairs in each block

- Presentation order counterbalanced for testing type, gender, face age, and names

Visual Attention

- Recorded using Eyelink 1000 eye-tracking camera during encoding \& testing

- Fixation count. Per face mean number fixations (focused gaze at $1^{\circ}$ visual angle for $\geq 100 \mathrm{~ms}$ )

- Looking time. Time spent fixating per face (ms) (Pupil $_{\text {Mean }}-$ Pupil $_{\text {Min }}$ )

- Normalized pupil size. Pupil size adjusted for individual variance $\left(\overline{\left(\text { Pupil }_{\text {Max }}-\text { Pupil }_{\text {Min }}\right)} \times 1 C\right.$

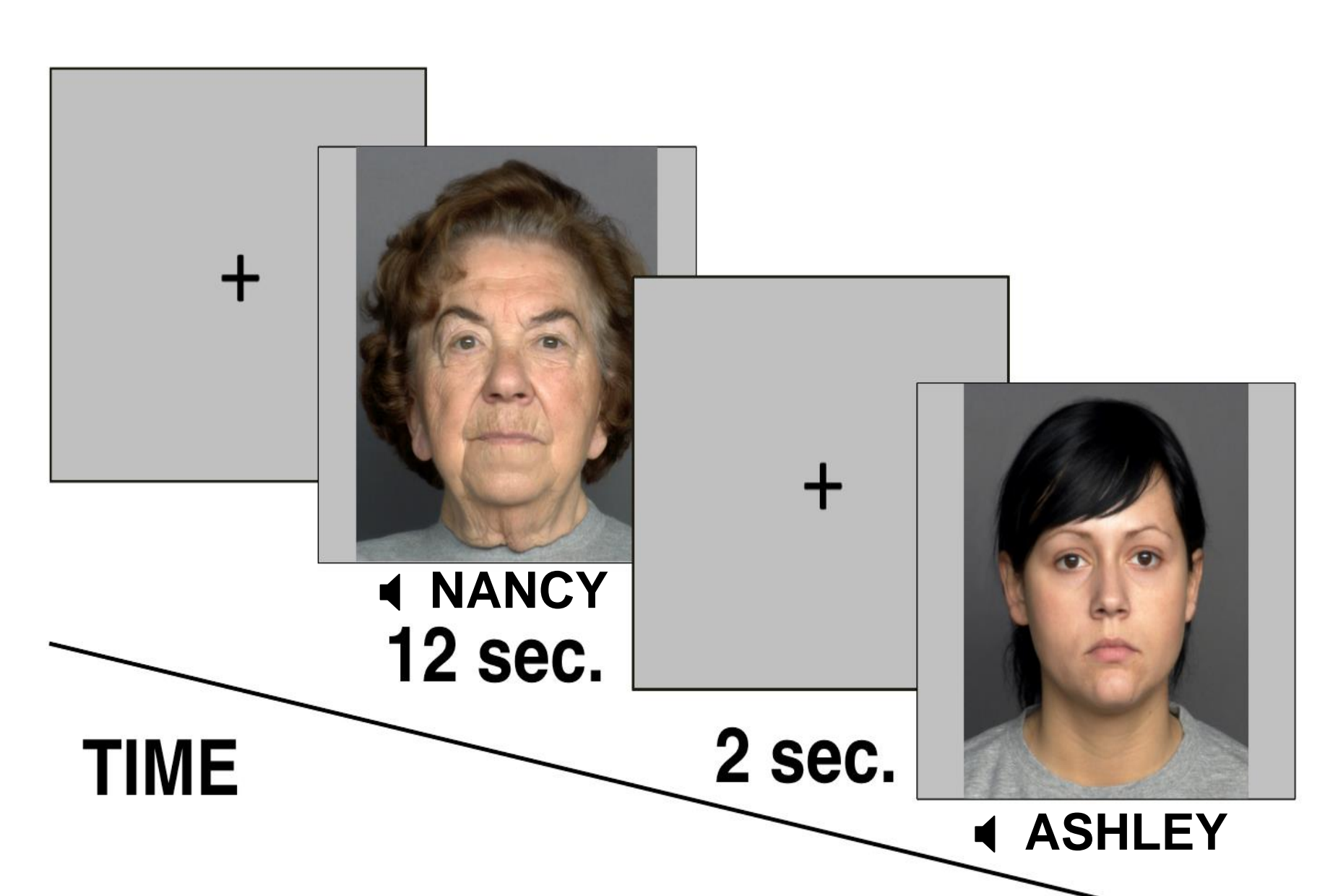

ENCODING

12 trials

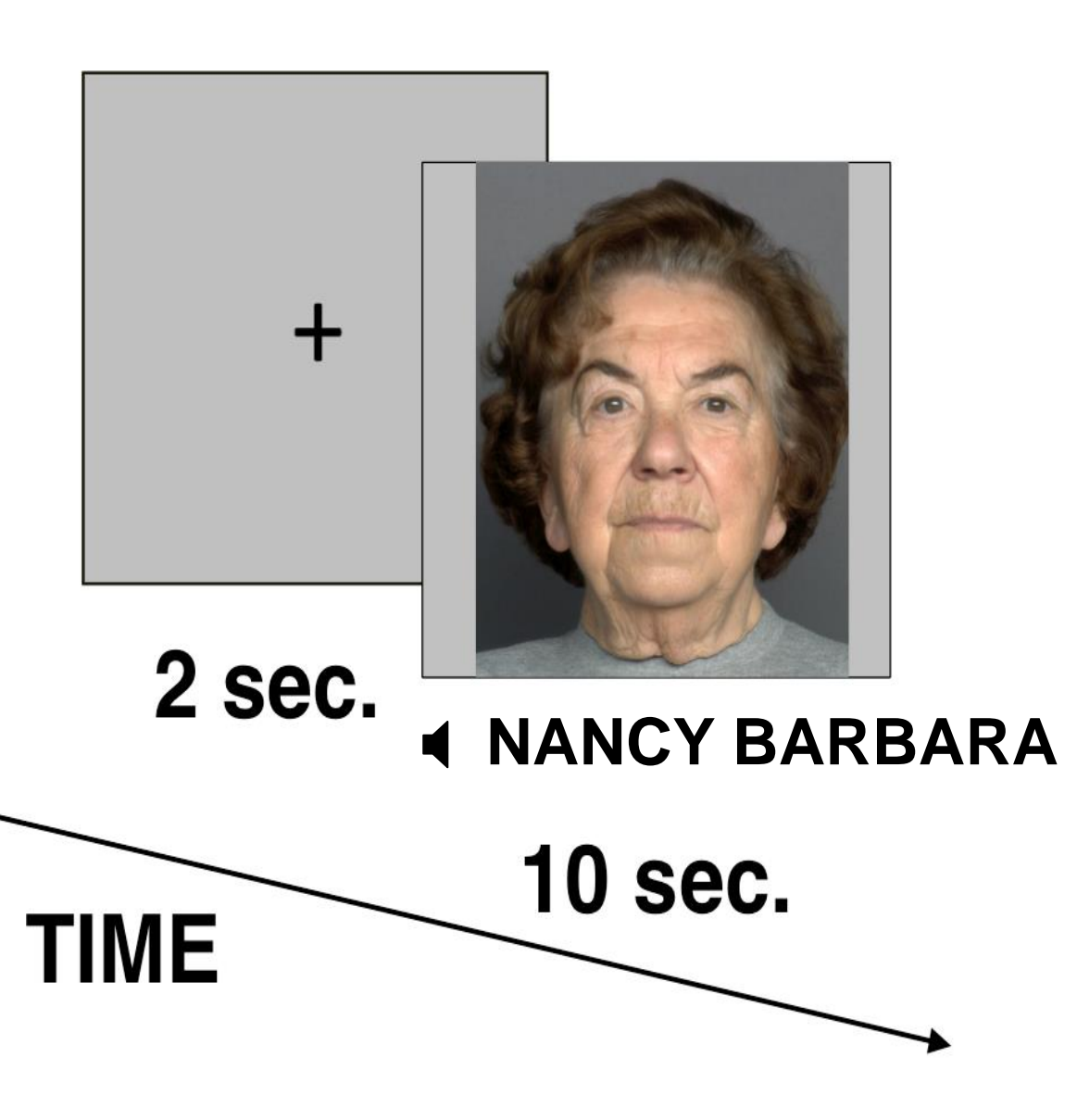

RECOGNITION

6 trials

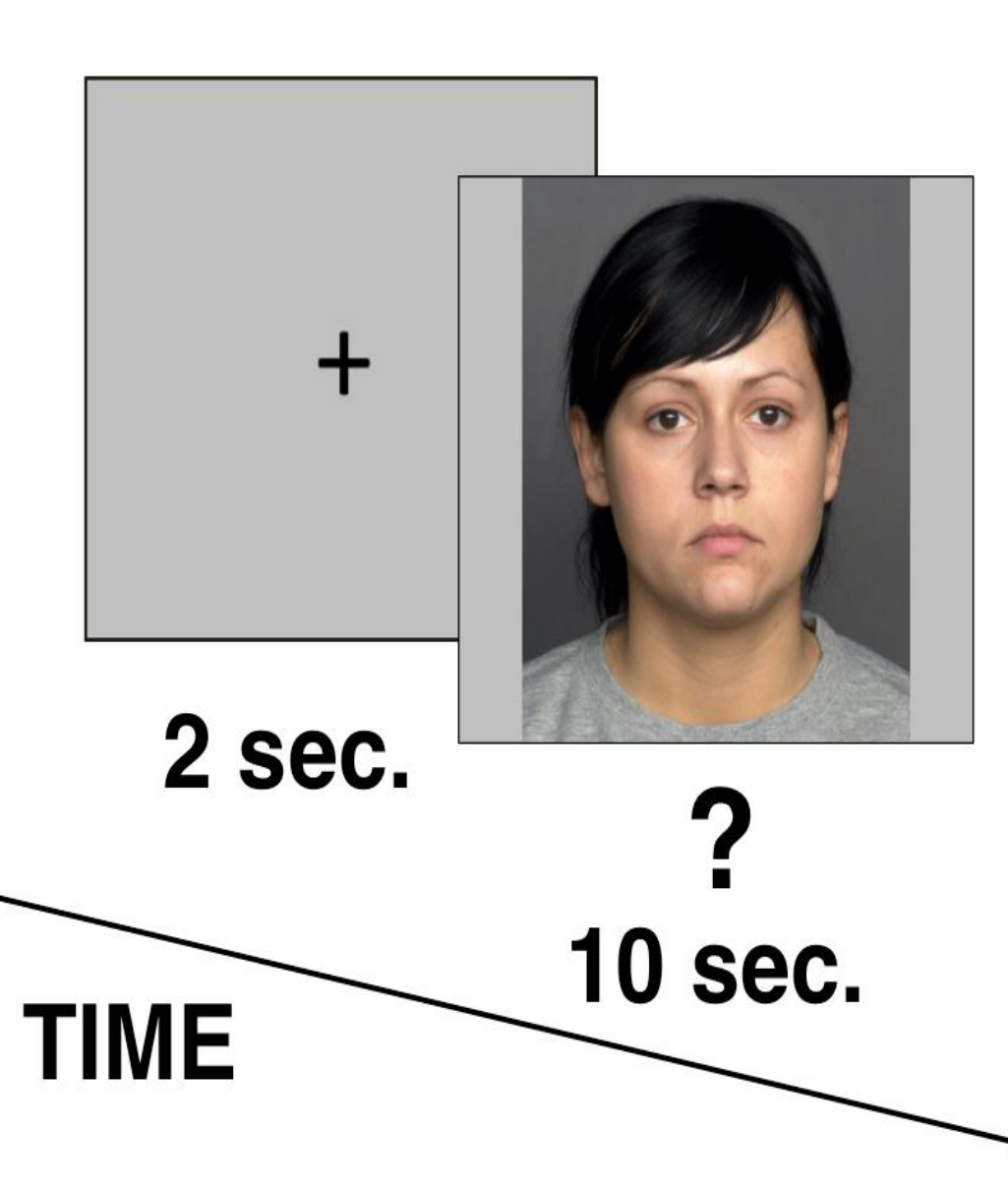

RECALL

\section{Design}

2 x 2 Mixed-Model Design

- Repeated measures ANOVAs

- 2 ages (between: YA, OA)

- 2 face ages (within: own, other)

Figure Information

Legend

Own-Age

Faces

Error bars $=95 \%$ confidence intervals

- ${ }^{*} p<.05$

$$
\text { 2 }
$$
- During testing but not encoding, younger adults
fixations for other-age versus own-age faces
2A. YA larger pupil size for 2A. YA larger pupil size for own- than
other-age faces; OA larger pupil size for other- than own-age faces

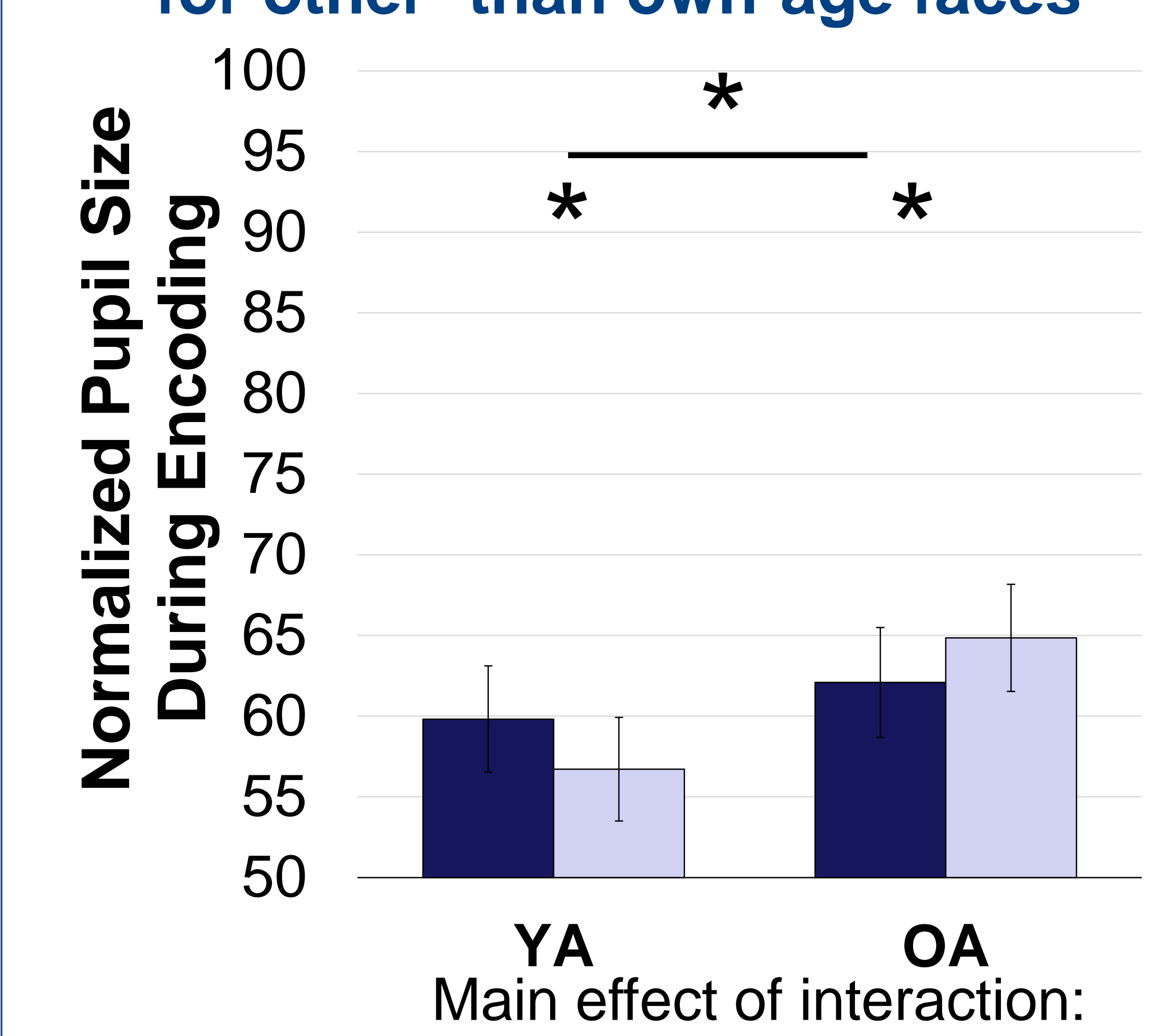
$F(1,172)=287.23, p<.01, \eta_{\mathrm{P}}^{2}=.625$

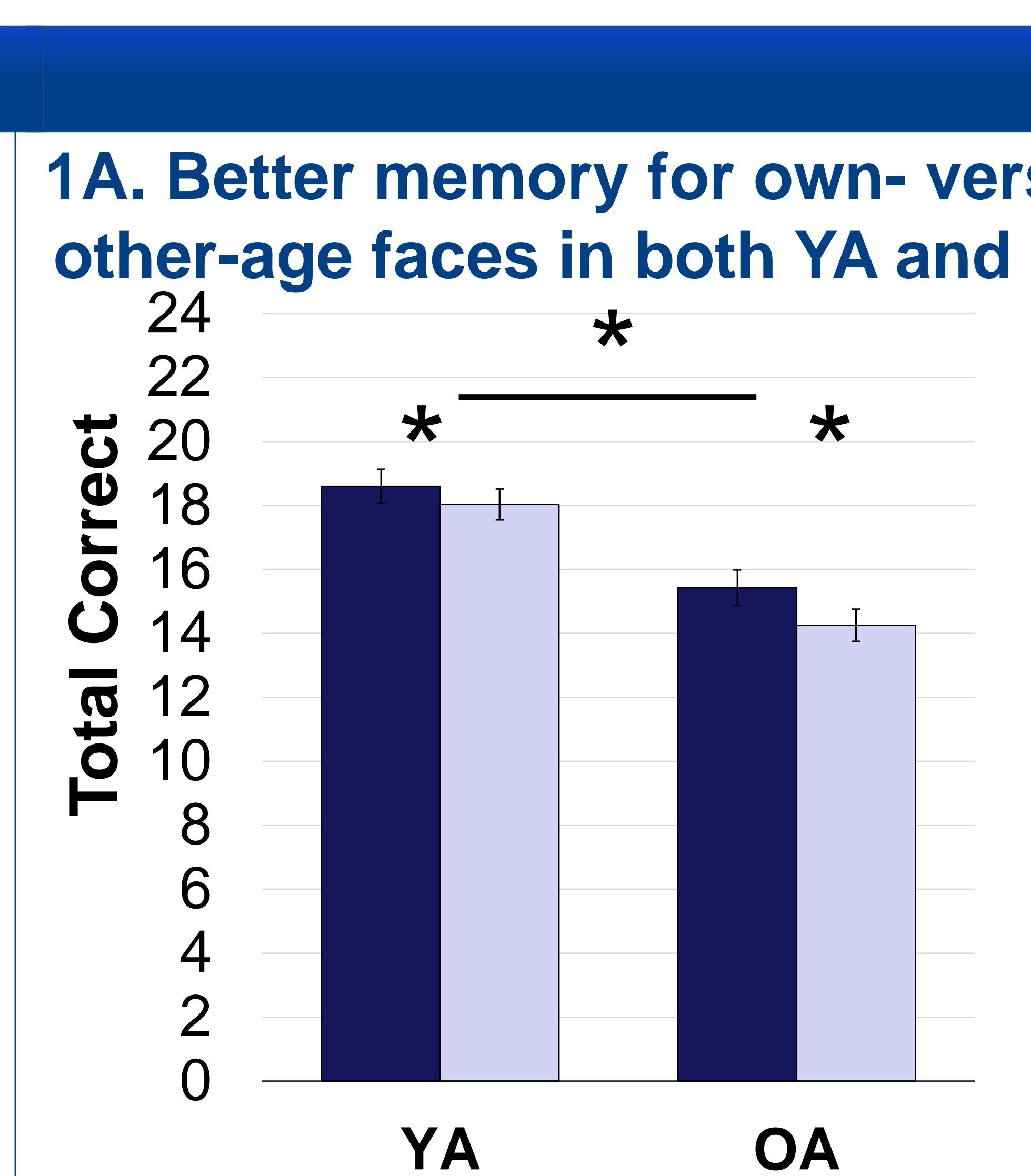

YA Main effect of face age:
172) $=27.28, p<.01, \eta_{p}^{2}=$

\section{Aim 1 Results}

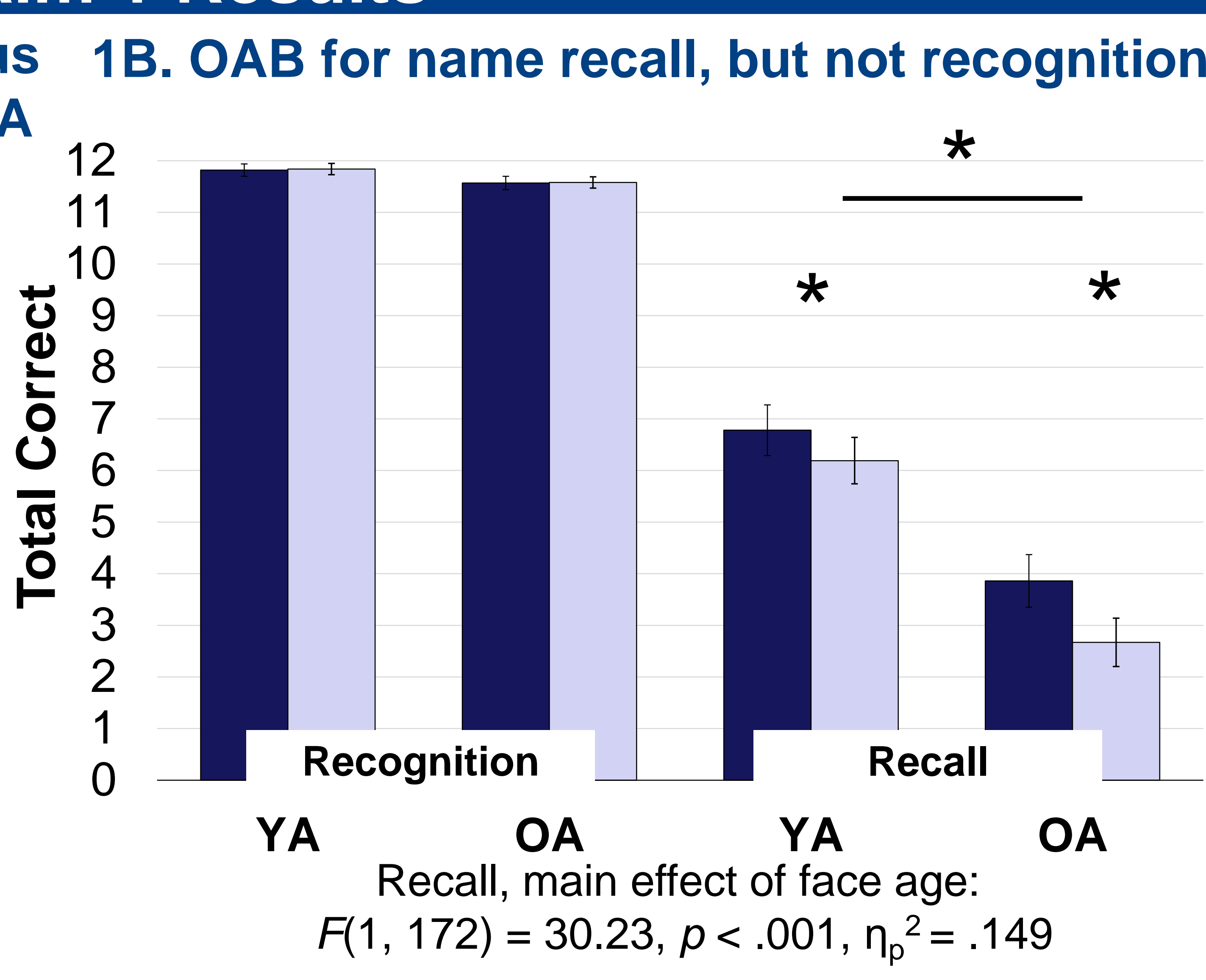

\section{Aim 2 Results}

$F(1,172)=30.23, p<.001, \eta_{p}^{2}=.149$

Younger adults look longer than older adults overall for encoding 2B. YA pupil size no difference for between face ages; OA larger pupil size for own- than other-age faces

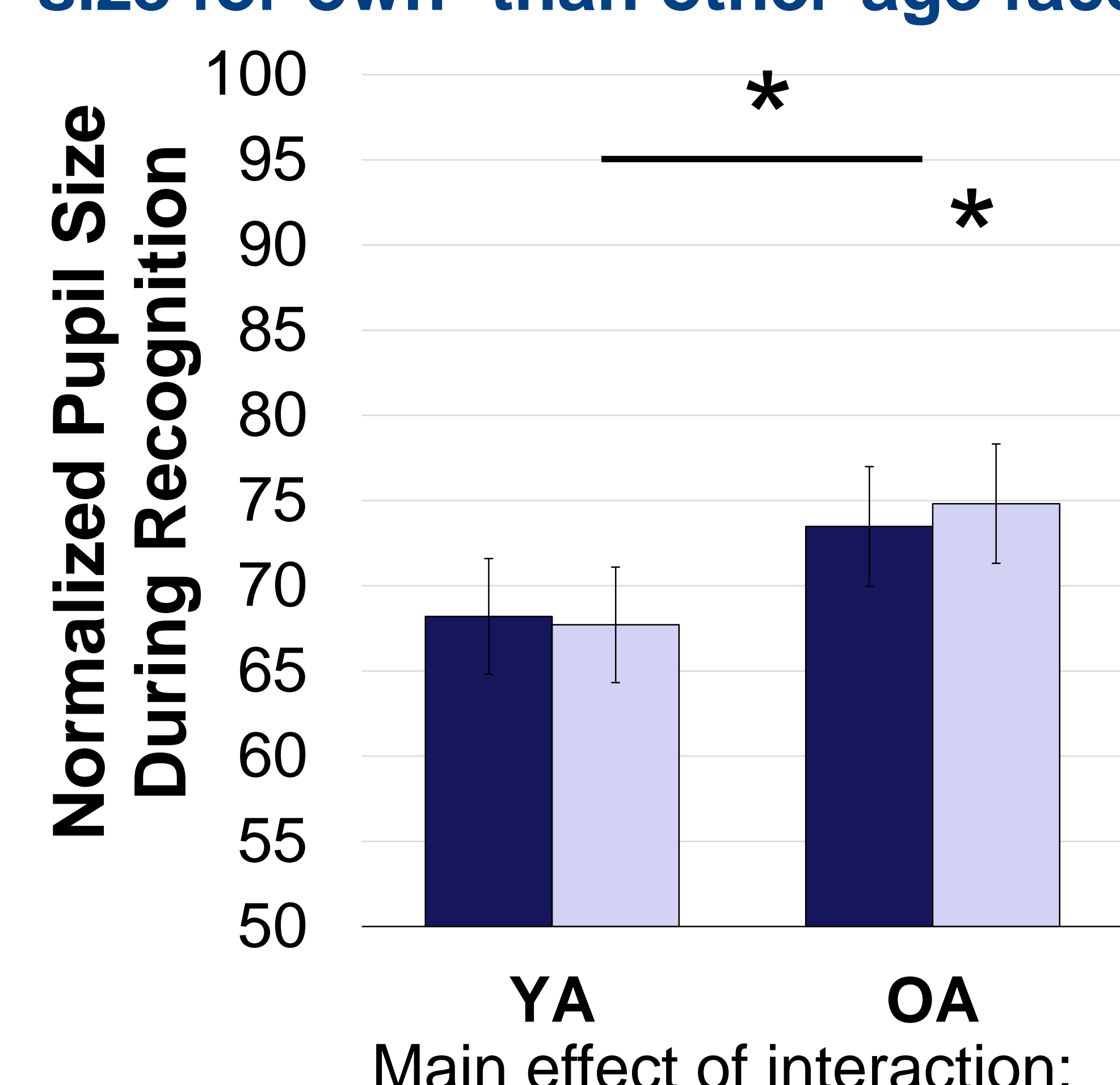

$F(1,172)=18.58, p<.01, \eta_{p}^{2}=.097$

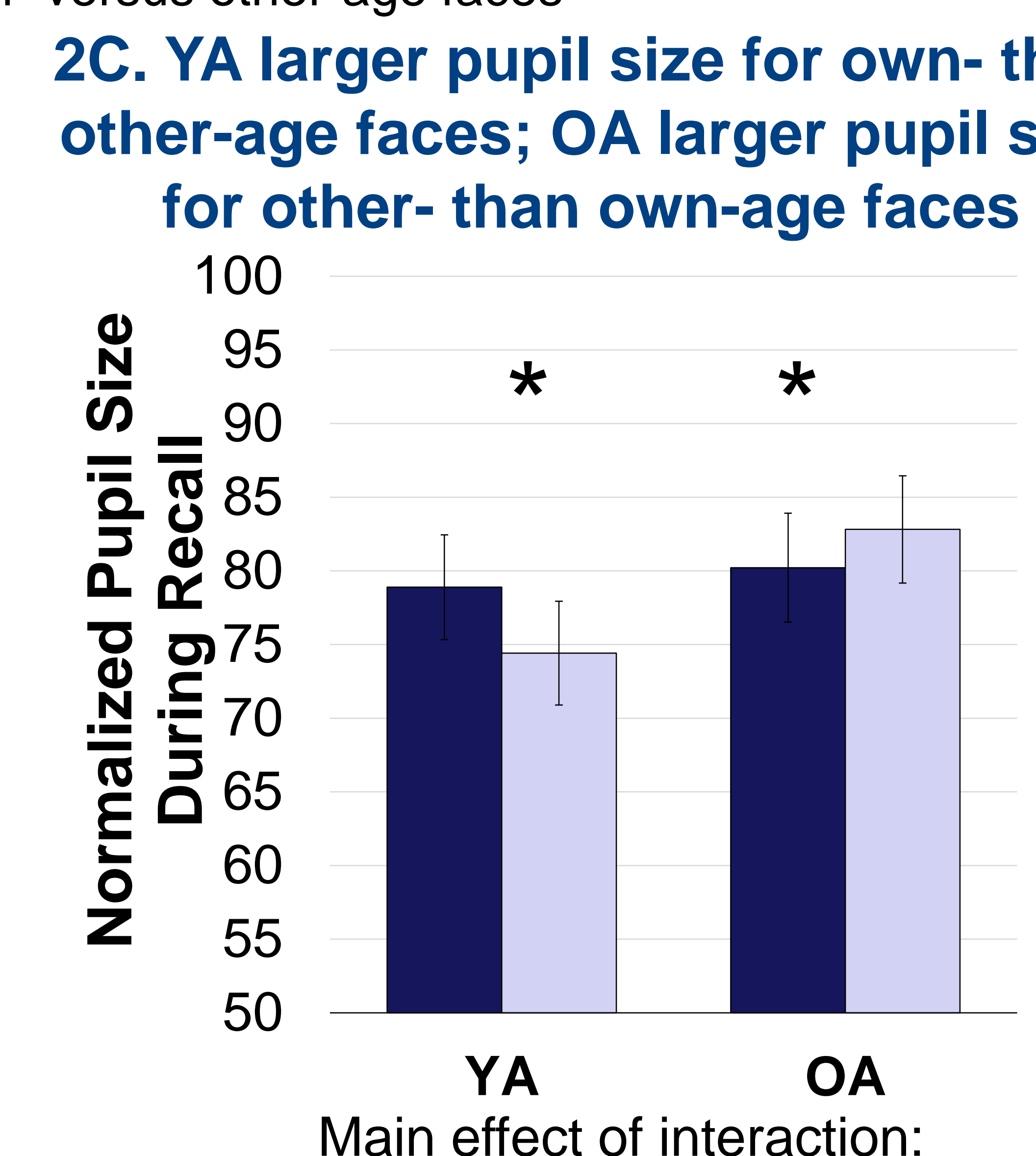

$F(1,172)=235.50, p<01, \mathrm{n}^{2}=578$

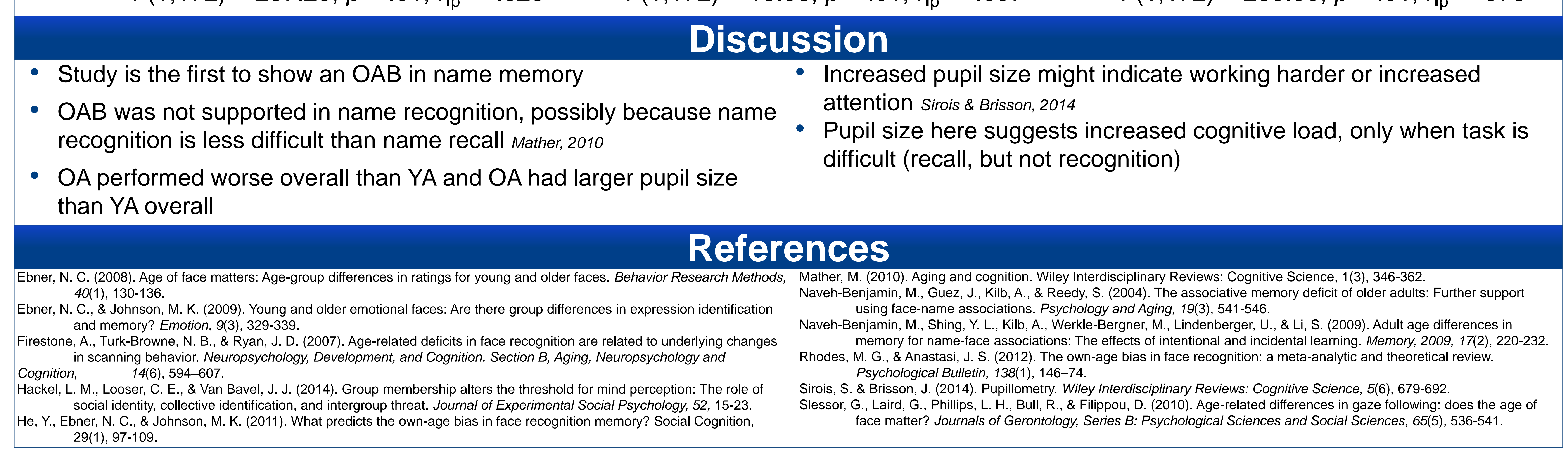

